\title{
STUDI KOMPARATIF TUTUPAN LIVING DAN NON LIVING SUBSTRAT DASAR PERAIRAN PULAU SEMPU KABUPATEN MALANG MENGGUNAKAN METODE REEF CHECK
}

\author{
Oktiyas Muzaky Luthfi ${ }^{\mathrm{a},}$, Dzikrillah Akbar ${ }^{\mathrm{a}}$, Muhammad Gilang Ramadhan ${ }^{\mathrm{a}}$, \\ Mujibur Rohman ${ }^{\mathrm{a}}$, Nur Kholis Wahib ${ }^{\mathrm{a}}$ \\ ${ }^{a}$ Program Studi Ilmu Kelautan Fakultas Perikanan dan Ilmu Kelautan \\ Universitas Brawijaya Malang \\ *Koresponden penulis : omuzakyl@ub.ac.id
}

\begin{abstract}
Abstrak
Penelitian ini dilaksanakan guna mensurvei substrat di perairan Sempu Kabupaten Malang menggunakan metode reefcheck (PIT: Point Intercept Transect). Substrat perairan dapat dibagi menjadi dua macam, antaralain living/substrat hidup (HC = Hard Coral/karang keras, SC = Soft Coral/karang lunak, NIA = Nutrient Indicator Algae/ alga, SP = Sponge/ spons, OT = Other/ organisme living lainnya) dan non living/ substrat tak hidup $(\mathrm{RC}=$ Rock/ batu, $\mathrm{RKC}=$ Recently Killed Coral/ karang yang baru mati, $\mathrm{RB}=$ Rubble/ Pecahan Karang, SI = Silt/ lumpur, SD = Sand/ pasir. Data penelitian diolah menggunakan perhitungan presentase tutupan karang pada setiap stasiun penelitian. Presentase tutupan karang stasiun Teluk Semut 1 menurun dari tahun 2016 ke 2018 sebesar $22.75 \%$ dan didominasi oleh substrat batu (52\%). Stasiun Teluk Semut 2 yang didominasi oleh substrat karang keras mengalami kenaikan presentase tutupan karang di tahun 2017 (42.37\%) dan menurun di tahun 2018 sebesar 41\%. Stasiun Waru-waru memiliki presentase tutupan karang 30\% dan didominasi oleh substrat pasir(44\%). Stasiun Watu Meja yang di dominasi oleh substrat pasir(53\%) mengalami kenaikan presentase tutupan karang di tahun 2017 (25.5\%) dan menurun sebesar 45\% di tahun 2018. Presentase tutupan karang dapat dipengaruhi oleh faktor alamiah maupun non alamiah, bahkan keterkaitan aktivitas antara substrat living dan non living di perairan Sempu dalam selang waktu dua tahun.
\end{abstract}

Kata Kunci : Sempu, PIT, presentase tutupan karang, substrat, living, non living

\begin{abstract}
This research was conducted to survey the substrate in Sempu waters, Malang Regency using a reefcheck method (PIT: Point Intercept Transect). Water substrate can be divided into two types, including living/ living substrate $(H C=$ Hard Coral hard coral, SC = Soft Coral $/$ soft coral, NIA = Nutrient Indicator Algael algae, $S P=$ Sponge/ sponge, $O T=$ Other/ living organisms other) and non living/ non-living substrate $(R C=$ Rock/ rock, Recently Killed Coral $R K C, R B=$ Rubble, SI = Silt/ mud, SD = Sand/ sand. Research data is processed using calculation of coral cover percentage at each research station The percentage of coral cover at Teluk Semut 1 station decreased from 2016 to 2018 by $22.75 \%$ and was dominated by stone substrate (52\%) Teluk Semut 2 station dominated by hard coral substrate experienced an increase in coral cover percentage in 2017 (42.37\%) and decreased in 2018 by 41\%, Waru-waru Station had a 30\% coral cover percentage and was dominated by sand substrate (44\%). Watu Station Table dominated by sand substrate (53\%) experienced increase in press entase of coral cover in $2017(25.5 \%)$ and decreases by $45 \%$ in 2018. Many factors affect the condition of coral cover percentage both naturally and non-naturally, even the linkages of activities between living and non living substrates in Sempu waters within two intervals year.
\end{abstract}

Keywords: Sempu, PIT, percentage of coral cover, substrate, living, non living 


\section{PENDAHULUAN}

Indonesia merupakan negara kepulauan yang memiliki luas lautan sebesar $70 \%$ dari luas keseluruhan negara. Indonesia merupakan habitat dari banyak spesies karang, dikarenakan iklim tropis Indonesia sangatlah cocok bagi pertumbuhan karang. Indonesia merupakan salah satu bagian dari negara "Coral Triangle" karena kekayaan terumbu karang yang dimiliki Indonesia sangatlah banyak. Coral Triangle di Indonesia berada di sepanjang perairan timur Pulau Jawa hingga perairan Papua. [1] Sebaran karang di Indonesia merata dari Sabang sampai Utara Jayapura, namun perairan dengan pertumbuhan karang yang baik berada di Sulawesi Maluku, Sorong, NTB, dan NTT.

Substrat merupakan susunan dasar perairan yang tersusun dari dua komponen, yaitu biotik dan abiotik. Contoh dari komponen biotik yang menyusun dasar perairan adalah karang, sedangkan contoh komponen abiotik yang menyusun dasar perairan adalah pasir dan lumpur [2]. [1] Terumbu karang adalah suatu ekosistem dasar perairan yang penyusun utamanya adalah scleractinian (karang batu). Secara umum kondisi terumbu karang yang teradapat di perairan Indonesia $6,39 \%$ dalam kondisi sangat baik, $23,40 \%$ dalam kondisi baik, $35,06 \%$ dalam kondisi cukup, dan 35,15\% dalam kondisi buruk [3].

Substrat dasar perairan dibagi menjadi dua kategori, yaitu living dan non living. Living merupakan kategori substrat dasar perairan yang terdiri dari karang keras, karang lunak, spons, dan alga. Non living merupakan kategori substrat dasar perairan yang terdiri dari karang yang baru mati, karang sudah lama mati, pecahan karang, pasir, dan lumpur [4]. Substrat living diperairan memiliki peran sebagai tempat tinggal, tempat memijah, dan tempat mencari makan berbagai biota laut. Selain itu, substrat living juga berperan dalam pembentukan ekosistem karang dan sumber kebutuhan bagi manusia [5].

Pulau Sempu secara adiministratif terletak di Desa Tambakrejo, Kecamatan Sumbermanjing Wetan, Kabupaten Malang, Jawa Timur. Secara geografis Pulau Sempu berada diantara $112^{\circ} 40^{\prime} 45^{\prime \prime}-112^{\circ} 42^{\prime} 45^{\prime \prime}$ bujur timur dan $8^{\circ} 27^{\prime} 24^{\prime \prime}-8^{\circ} 24^{\prime} 54^{\prime \prime}$ lintang selatan. Pulau Sempu merupakan salah satu wilayah konservasi dengan status cagar alam yang berada di Jawa Timur. Kondisi substrat di perairan Pulau Sempu mengalami peningkatan, pada penelitian yang dilakukan tahun 2016 substrat di perairan Pulau Sempu dalam kondisi rusak kemudian pada penelitian yang dilakukan tahun 2017 substrat di perairan Pulau Sempu kondisinya meningkat menjadi baik. Berdasarkan study pustaka yang dilakukan kondisi living dan non living pada tahun 2016-2017 di perairan Pulau Sempu keduanya mengalami penurunan [6]; [7]. Pengamatan kondisi substrat dasar perairan dapat dilakukan dengan berbagai macam metode, salah satunya metode Point Intercept Transect (PIT) yang dikembangkan oleh Reef Check. [8] Metode PIT digunakan untuk memperkirakan kondisi substrat disuatu lokasi berdasarkan persen living. Tujuan dari penelitian ini adalah untuk mengetahui kondisi tutupan karang pada tahun 2016 hingga 2018 dengan mengaitkan antara substrat living dan non living di perairan Pulau Sempu.

\section{BAHAN DAN METODE}

Pengambilan data penelitian dilakukan pada 28 April 2018 di Cagar Alam Pulau Sempu, Desa Tambakrejo, Kecamatan Sumbermanjing Wetan, Kabupaten Malang, Jawa Timur. Terdapat empat stasiun dalam pengambilan data penelitian, yakni stasiun satu hingga empat secara berurutan antara lain Teluk Semut $1\left(112.68203^{\circ} \mathrm{BT}-08.43913^{\circ}\right.$ LS), Teluk Semut $2\left(112.68082^{\circ}\right.$ BT $\left.08.44010^{\circ} \mathrm{LS}\right)$, Waru-waru $\left(112.69370^{\circ} \mathrm{BT}-\right.$ $\left.08.43005^{\circ} \mathrm{LS}\right)$ dan Watu Meja $\left(112.69814^{\circ}\right.$ $\left.\mathrm{BT}-08.42895^{\circ} \mathrm{LS}\right)($ Gambar 1).

Metode pengambilan data substrat digunakan untuk menggambarkan bagaimana kondisi substrat yang ada di daerah penelitian. [9] Mengambil data substrat dapat dilakukan dengan menggunakan metode antaralain metode transek garis (Line Transect), metode transek kuadrat, metode Manta Tow dan Metode Transek Sabuk (Belt transek). Metode pengambilan data substrat juga dapat dilakukan dengan menggunakan metode PIT (Point Intercept Transect) (Reefcheck.org). 


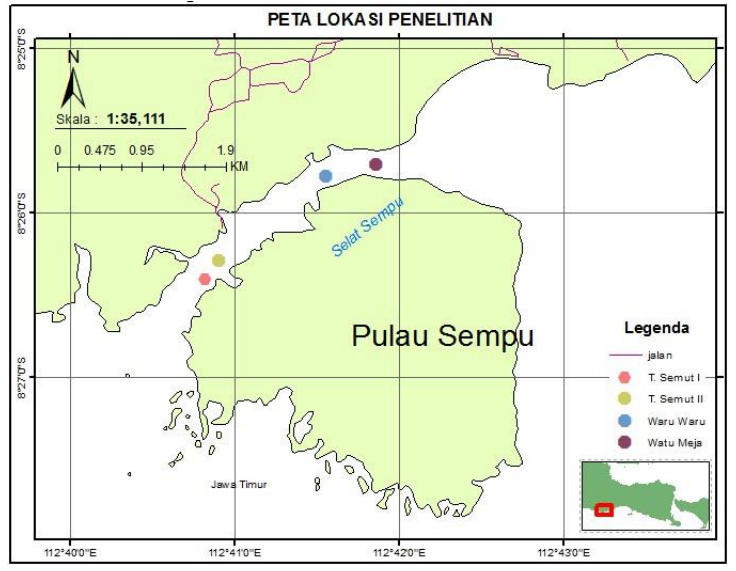

Gambar 1. Peta Lokasi Penelitian, Pulau Sempu

Metode PIT dilakukan dengan cara membentangkan roll meter sepanjang 100 meter, dimana dalam satu garis tersebut terbagi menjadi 4 segmen dengan panjang 25 meter. Pada tiap ujung segmen terdapat blank space sepanjang 5 meter guna interpolasi data. Pencatatan objek substrat dilakukan pada interval 0.5 meter pada garis transek. Sehingga pengambilan data dapat dimulai dari 0 meter, 0.5 meter, 1 meter, 1,5 meter, 2 meter hingga titik 5 meter terakhir pada tiap segmennya (Gambar 2). Dari setiap segmen terdapat 40 titik substrat yang tercatat, sehingga total dalam satu transek PIT terdapat 160 titik substrat yang tercatat [10]. Metode PIT dianggap lebih sederhana dan mudah untuk dipahami dibanding metode yang lain, namun metode ini lebih terukur. [11] Metode PIT dapat menghasilkan presentase tutupan karang dengan membutuhkan waktu yang singkat dan hasil yang efisien.

Pencatatan data dilakukan dengan melihat objek substrat yang sesuai dengan kategori reef check. Kategori reef check tersebut meliputi karang keras (HC), karang lunak (SC), karang yang baru saja mati (RKC), alga indikator nutrien (NIA), Spons (SP) dan lainnya (OT) sebagai golongan kategori substrat living serta batu (RC), patahan karang (RB), pasir (SD) dan lumpur (SI) sebagai golongan substrat non living [10].

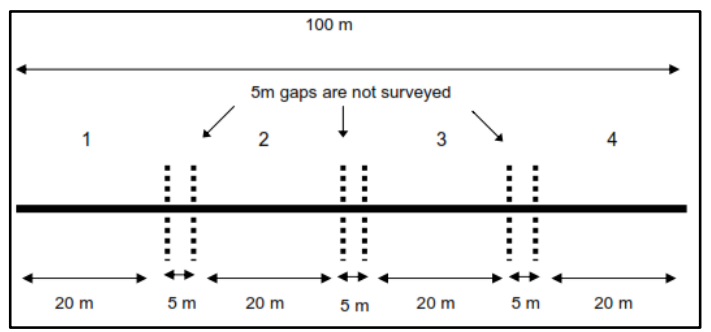

Gambar 2. Metode PIT (Hodgson et al., 2006)

Pengolahan Data

Presentase tutupan substrat dapat dihitung dengan menggunakan rumus sebagai berikut [10] :

$$
C=\frac{\Sigma(\mathrm{i})}{A} \times 100 \%
$$

Keterangan:

C : Tutupan Substrat

$\Sigma(\mathrm{i}) \quad$ : Jumlah titik setiap tipe substrat

A : Jumlah total kisi yang digunakan dalam pengambilan data (160 titik).

\section{HASIL DAN PEMBAHASAN}

Berdasarkan pengukuran yang telah dilakukan di empat stasiun penelitian mulai dari stasiun Teluk Semut 1, Teluk Semut 2, Waru - Waru dan Watu Meja didapat data substrat seperti yang ditampilkan pada (Tabel 1). Pengamatan substrat yang dilakukan pada setiap lokasi pengamatan dilakukan dengan melihat substrat tepat di bawah titik pengamatan dan dilakukan sepanjang garis transek penelitian (PIT). Pelaksanaan metode ini menggunakan poin pengamatan tiap 0.5 meter, sepanjang grais transek $100 \mathrm{~m}$. 


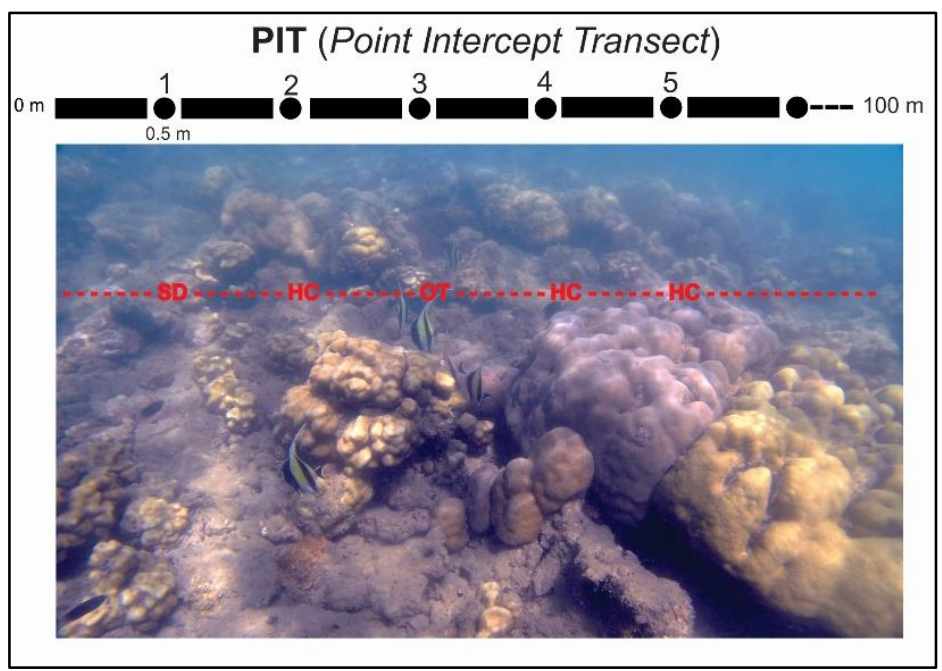

Gambar 3. Skema cara kerja dengan metode PIT

Berdasarkan sifatnya, substrat yang menjadi indikator dalam penelitian terbagi menjadi dua, yaitu substrat hidup, dan substrat mati, sehingga persentase substrat akan terbagi menjadi dua kelompok, yaitu living dan living. Kategori substrat yang masuk dalam kelompok living cover yaitu, Hard Coral (HC), Soft Coral (SC) , Nutrient Indikator Algae (NIA), Sponge (SP) dan Other (OT), sedangkan substrat yang masuk dalam kelompok non living cover yaitu, recently killed coral (RKC), rock $(R C)$, Rubble (RB), Sand (SD) dan Silt (SI) (Tabel 1).

Hasil monitoring pada stasiun Teluk Semut I tahun 2016 tutupan karang keras adalah 33,75\% [12] . Pada tahun 2017 dilokasi yang sama tutupan karang keras adalah $12 \%$ [7]. Pada tahun 2018 dilokasi stasiun yang sama tutupan karang keras sebesar $11 \%$
(Gambar 6). Ditemukan karang keras pada Teluk Semut I yaitu karang jenis life form foliose (Echinopra lamellosa, Monthipora sp.) dan massive. Stasiun Teluk Semut I memiliki nilai substrat living dengan tutupan paling tinggi adalah Hard Coral (HC) dengan nilai sebesar $11 \%$ sedangkan untuk substrat non living dengan tutupan paling tinggi adalah Rock (RC) dengan nilai sebesar 52\% (Gambar 5). Faktor penurunan yang terjadi diduga dampak antropogenik dibandingkan dengan peristiwa alamiah seperti penaikan atau penurunan muka laut secara ekstrim, proses predasi, dan pemanasan global. Hal ini menunjukkan besarnya pengaruh manusia dalam jangka panjang terhadap eksistensi di ekosistem terumbu karang [13]. 
Tabel 1. Data Substrat Pada Setiap Stasiun Penelitian

\begin{tabular}{|c|c|c|c|}
\hline Stasiun & Kategori & Tipe & Jumlah \\
\hline \multirow{10}{*}{ Teluk Semut 1} & \multirow{5}{*}{ Living } & $\mathrm{HC}$ & 18 \\
\hline & & SC & 0 \\
\hline & & NIA & 2 \\
\hline & & $\mathrm{SP}$ & 0 \\
\hline & & OT & 1 \\
\hline & \multirow{5}{*}{ Non - living } & RKC & 0 \\
\hline & & $\mathrm{RC}$ & 83 \\
\hline & & $\mathrm{RB}$ & 31 \\
\hline & & SD & 25 \\
\hline & & SI & 0 \\
\hline \multirow{10}{*}{ Teluk Semut 2} & \multirow{5}{*}{ Living } & $\mathrm{HC}$ & 49 \\
\hline & & $\mathrm{SC}$ & 0 \\
\hline & & NIA & 1 \\
\hline & & $\mathrm{SP}$ & 0 \\
\hline & & OT & 1 \\
\hline & \multirow{5}{*}{ Non-living } & RKC & 2 \\
\hline & & $\mathrm{RC}$ & 49 \\
\hline & & $\mathrm{RB}$ & 36 \\
\hline & & SD & 23 \\
\hline & & SI & 0 \\
\hline \multirow{10}{*}{ Waru - Waru } & \multirow{5}{*}{ Living } & $\mathrm{HC}$ & 48 \\
\hline & & $\mathrm{SC}$ & 0 \\
\hline & & NIA & 0 \\
\hline & & $\mathrm{SP}$ & 2 \\
\hline & & OT & 5 \\
\hline & \multirow{5}{*}{ Non-living } & RKC & 0 \\
\hline & & $\mathrm{RC}$ & 34 \\
\hline & & $\mathrm{RB}$ & 28 \\
\hline & & $\mathrm{SD}$ & 71 \\
\hline & & SI & 0 \\
\hline \multirow{10}{*}{ Watu Meja } & \multirow{5}{*}{ Living } & $\mathrm{HC}$ & 12 \\
\hline & & $\mathrm{SC}$ & 3 \\
\hline & & NIA & 0 \\
\hline & & $\mathrm{SP}$ & 0 \\
\hline & & OT & 4 \\
\hline & \multirow{5}{*}{ Non-living } & RKC & 0 \\
\hline & & $\mathrm{RC}$ & 45 \\
\hline & & $\mathrm{RB}$ & 16 \\
\hline & & SD & 84 \\
\hline & & SI & 0 \\
\hline
\end{tabular}




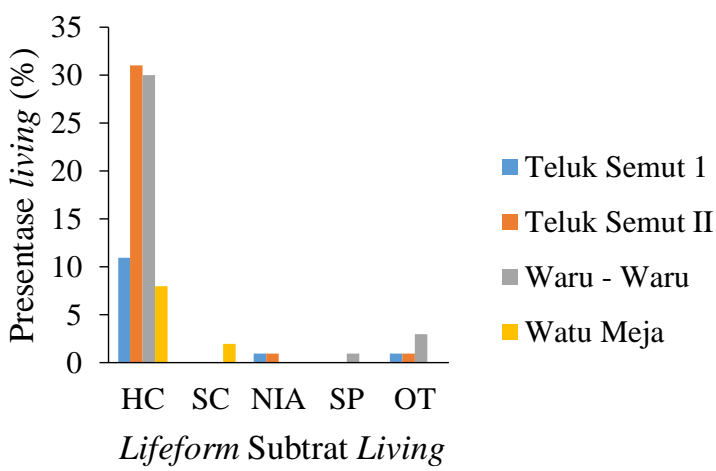

Gambar 4. Tutupan Substrat Living cover di Perairan Pulau Sempu 2018

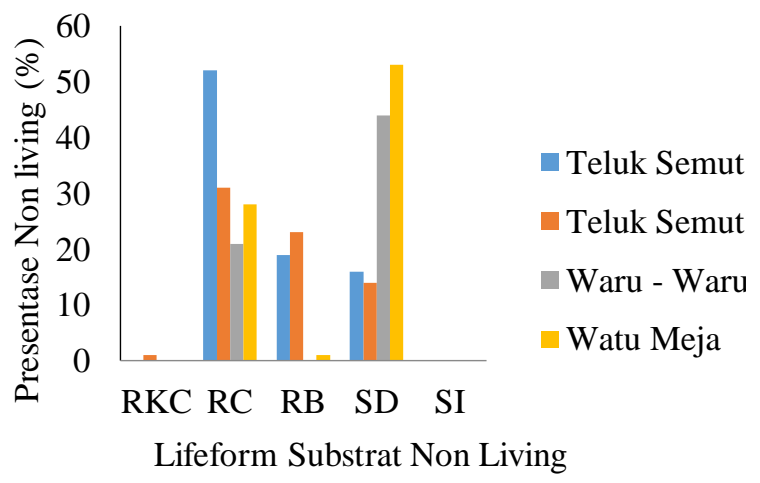

Gambar 5. Tutupan Substrat Non Living di Perairan Pulau Sempu 2018

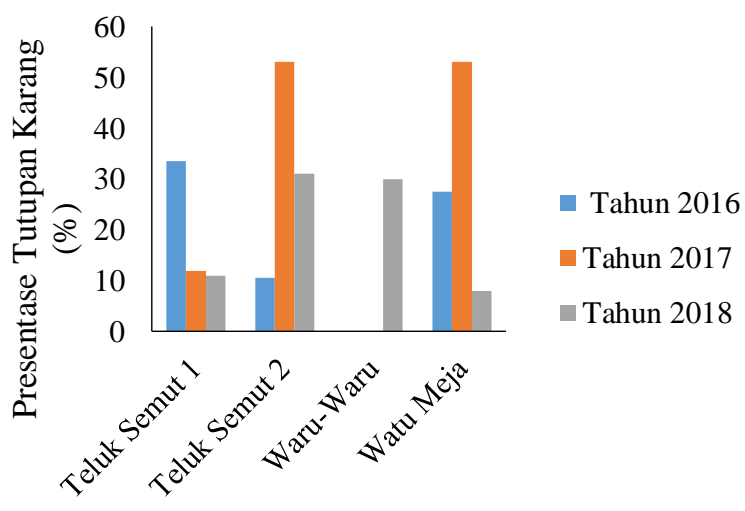

Gambar 6. Presentase tutupan karang tahun 2016, 2017 dan 2018

Presentase substrat non living $\mathrm{RC}$ tahun 2016 yaitu $4.375 \%$ dan pada tahun 2017 yaitu 21\%. Tututpan RC tahun 2018 yaitu $52 \%$ peningkatan substrat batu (RC) yang juga dapat diduga akibat proses sedimentasi oleh pasir dan kompetisi oleh alga $(<3 \mathrm{~cm})$ pada karang yang hidup sebelumnya. Hal ini dapat dilihat dari substart batu itu sendiri yang merupakan bekas skeleton karang yang sudah di tumbuhi oleh alga dan sebagian tertututp oleh pasir. [14] Sedimentasi akan mengurangi penetrasi cahaya matahari dan mengganggu zooxanthellae karang untuk fotosintesis. Alga sebagai kompetitor utama terumbu karang bersaing dalam hal ruang dan cahaya yang masuk dalam perairan [12].

Tutupan karang keras stasiun Teluk Semut II tahun 2016 adalah 10,625\% [12]. Pada tahun 2017 tutupan karang keras adalah $53 \%$ [7]. Tahun 2018 presentase tutupan karang keras menurun, dengan nilai presentase 31\% (Gambar 6). Substrat living di dominasi oleh karang keras (HC), dan substrat non living di dominasi kembali oleh batu (RC) dengan presentase tutupan 31\% (Gambar 5). Stasiun Teluk Semut II memiliki tutupan presentase karang tertinggi dari semua stasiun penelitian ini. Substrat non living jenis pecahan karang (RB) juga memiliki nilai presentase tertinggi $(23 \%)$ dari nilai tutupan RB stasiun lainnya. Pecahan karang yang di temukan berasal dari fragmen karang dengan life form acropora dan foliose. [15] Rubble (RB) dapat ditemukan di suatu perairan diakibatkan oleh predasi organisme, penyakit, bioerosi dan keadaan perairan yang tak stabil (extreme).

Bukan tidak mungkin terumbu karang akan rusak akibat perilaku manusia, pada penelitian ini banyak ditemukan alat tangkap (benang pancing) yang tersangkut pada karang dan bekas jangkar yang tersangkut pada bebatuan. [16] Pecahan karang memiliki sifat yang dinamis, mudah bergeser atau dipindahkan oleh gelombang dan arus. Maka dari itu susah untuk membedakan pecahan karang yang timbul akibat aktivitas alami maupun akibat aktivitas manusia.

Stasiun Waru-Waru merupakan stasiun yang baru pertama kali dilakukan penilitian. Stasiun ini memiliki tutupan karang keras 30\% (Gambar 4) yang sekaligus menjadi substrat living yang mendominasi. Stasiun ini di dominasi oleh substrat non living yakni pasir (SD) dengan nilai sebesar $44 \%$. Stasiun ini merupakan stasiun penelitian terdalam dari stasiun lainnya. Subtrat non living pasir (SD) mendominasi akibat stasiun Waru-Waru merupakan perairan dengan tipe slope. [10] Survei substrat dapat dilakukan pada dua kontur kedalaman yakni kedalaman dangkal (2-6 meter) dan kedalaman menengah (>6-12 meter). Pemantauan tergolong kategori survey menengah karena dilakukan pada pemantauan 
kedalaman 7 meter. Pada kedalaman ini, tidak banyak karang yang dapat survive karena faktor terbatasnya penetrasi cahaya dan sedimentasi akibat dominasi substrat nonliving pasir (SD).

Karang yang mendominasi di stasiun Waru-Waru adalah karang dengan life form massive (Porites lutea). Kondisi karang Porites lutea sendiri tergolong tidak sehat, banyak ditemukan koloni karang yang terkena penyakit pink line syndrome. Penelitian ini juga menemukan Christmas tree worm (Spirobranchus giganteus) sebagai kategori substart living other (OT) tertinggi (3\%) didapati pada semua koloni Porites lutea. [17] Karang Porites lutea dan Porites lobata yang bersimbiosis dengan Christmas tree worm dapat mengurangi dampak sedimentasi. Pernyataan ini sesuai dengan kondisi stasiun yang didominasi oleh substrat non living pasir (SD).

Hasil monitoring pada stasiun Watu Meja tahun 2016 tutupan karang keras adalah 27,5\% [17]. Pada tahun 2017 tutupan karang keras meningkat dengan nilai presentase 53\% [7]. Pada tahun 2018 tutupan karang keras menurun secara signifikan dengan presentase tutupan $8 \%$ (Gambar 6). Substrat non living tertinggi dengan presentase $53 \%$ oleh pasir (SD) (Gambar 5). Substrat pasir diduga berasal dari pecahan karang (RB) yang terbawa arus. Stasiun ini memiliki topografi perairan slope, serta memiliki arus yang kuat karena jauh dari teluk dan menghadap secara langsung pada samudera Pasifik. Guna mengutamakan faktor keselamatan, pengaatan substrat di stasiun ini dilakukan di kedalaman 1.5 meter.

Nilai tutupan substrat sendiri setiap tahunnya mengalami fenomena kurva yang tidak stabil. Terdapat komposisi karang keras yang berbeda dan mendominasi tiap stasiun. Tipologi karang dengan massive slow growht coral, yakni karang Poritiids, faviids, dan Fungiids yang memiliki laju pertumbuhan lama [6]. Karang dengan jenis lifeform bercabang memiliki pertumbuhan yang cepat $\left(5.23 \mathrm{~cm}^{2}\right)$ [18], dan karang dengan lifeform lembaran tergolong memiliki pertumbuhan yang cepat pula meskipun tidak secepat karang bercabang [19]. [18] Ekosistem terumbu karang pada perairan Sendang Biru mengalami penurunan, hal tersebut terjadi akibat beberapa kegiatan antropogenik (destructive fishing, kegiatan pariwisata) dan secara alami (sedimentasi, naiknya suhu perairan).

\section{KESIMPULAN}

Berdasarkan analisa komparsi survei tutupan karang yang dilakukan pada tahun 2016, 2017 dan 2018 dapat di simpulkan bahwa terjadi fluktasi presentase tutupan karang di Cagar Alam Pulau Sempu. Presentase tutupan karang meningkat pada tahun 2016 menuju 2017, dan turun secara signifikan di tahun 2018 dengan kondisi "buruk" (Teluk Semut I: 11\% ; Teluk Semut II: 31\%; Waru-Waru: 30\%; Watu Meja :8\%). Kondisi tutupan karang yang buruk ditandai dengan dominasi substrat non living seperti batu dan pasir di stasiun pengamatan.

\section{Ucapan Terimakasih}

Terimakasih penulis ucapkan kepada Kementrian Kelautan dan Perikanan UPP Pondok Dadap Sendang Biru yang telah memberikan sarana guna melancarkan jalannya penelitian Reefcheck di perairan Sempu. Terimakasih pula penulis ucapkan kepada seluruh mahasiswa Selam Keahlian 2018 yang telah membantu melaksanakan jalannya penelitian Reffcheck ini.

\section{DAFTAR PUSTAKA}

[1] Suharsono, "Jenis-jenis karang di Indonesia," Coremap Program., LIPI Jakarta, 2008.

[2] Ariyati, R.W., Sya'rani, dan L., Arini, E., "Analisis Kesesuaian Perairan Pulau Karimunjawa Dan Pulau Kemujan Sebagai Lahan Budidaya Rumput Laut Menggunakan Sistem Informasi Geografis 19," 2007.

[3] Giyanto, Abrar, M., Hadi, T.A., Hafizt, M., Salatalohy, A., dan Iswari, M.Y., "Status Terumbu Karang Indonesia 2017," Puslit Oseanografi - LIPI., Jakarta, 2017.

[4] Hodgson, G. (Ed.), "Reef check intruction manual: a guide to reef check coral reef monitoring," Reef Check, Inst. of the Environment., Los Angeles [Calif.], 2004.

[5] Luthfi, O.M., Yulianto, F., Pangaribuan, S.P.C., Putranto, D.B.D., Alim, D.S., 
dan Sasmitha, R.D., "Kondisi Substrat Dasar Perairan Cagar Alam Pulau Sempu, Kabupaten Malang,” 2018.

[6] Luthfi, O.M., Januarsa, I.N., Fajri, H., Muhammad, F., Aji, A.T., Jumantry, S., Kusuma, M.I.A., Algadri, G.A., Roganda, F., Rizal, M.F.A., dan Setyo, A., 2017. "Substrates monitoring using reef check method in Sempu Strait Waters, Malang Regency," vol. 6, no. 9, 2017.

[7] Luthfi, O.M., Yulianto, F., Pangaribuan, S.P.C., Putranto, D.B.D., Alim, D.S., dan Sasmitha, R.D., "Kondisi Substrat Dasar Perairan Cagar Alam Pulau Sempu, Kabupaten Malang,” 2019.

[8] Afandy, Z., "Kondisi Terumbu Karang Di Pesisir Barat Pulau Kei Kecil, Kabupaten Maluku Tenggara," vol.5, no.7, 2014.

[9] Johan, Ofri, "Metode Survei Terumbu Karang Indonesia," Training course., Biologi Karang, 2003.

[10] Hodgson, G., Hill, J., Kiene, W., Maun, L., Mihaly, J.,Liebeler, J., Shuman, C., dan Torres, R.. "Reef check instruction manual: a guide to reef check coral reef monitoring," Reef Check Foundation., Pacific Palisades, California USA, 2006.

[11] Souhoka J dan Picasauw J., "Studi Baseline Terumbu Karang di Lokasi DPL Kabupaten Selayar Tahun 2008," COREMAP - LIPI, Jakarta, 2008

[12] Luthfi, O.M., "Pemantauan Kondisi Substrat Menggunakan Metode Reef Check di Perairan Selat Sempu, Kabupaten Malang,". Depik., no.6, hal. 72-80, 2017

[13] Toruan, L.N.L., dan Soedharma, D., "Komposisi dan Distribusi Foraminifera Bentik di Ekosistem Terumbu Karang pada Kepulauan Seribu," Jurnal Ilmu Dan Teknologi Kelautan Tropis., vol. 5, no. 16, 2013.

[14] Fachrurrozie, A., Patria, M.P., "Pengaruh Perbedaan Intensitas Cahaya terhadap Kelimpahan Zooxanthella pada Karang Bercabang (Marga:Acropora) di Perairan Pulau Pari, Kepulauan Seribu,"
Jurnal Akuatika., vol 3, 2. ISSN 08532523. 115-124, 2012.

[15] Holmes, K.E., Edinger, E.N., Hariyadi, Limmon, G.V., dan Risk, M.J., "Bioerosion of Live Massive Corals And Branching Coral Rubble On Indonesian Coral Reefs,". Marine Pollution Bulletin., no. 40, hal. 606617, 2000 .

[16] Fox, H.E., Pet, J.S., Dahuri, R., dan Caldwell, R.L., 2003. "Recovery In Rubble Fields: Long-Term Impacts of Blast Fishing," Marine Pollution Bulletin., no. 46, hal. 1024-1031, 2003.

[17] Luthfi, O.M., dan Yamindago, A., "Telaah Struktur Komunitas Terumbu Karang Sebagai Studi Awal Program Rehabilitasi Terumbu Karang di Perairan Pasir Putih Situbondo," 2008.

[18] Luthfi, O. M, "Coral Reef Conservation Using Coral Garden Initiative In Sempu Island," Journal of Innovation and Applied Technology., vol. 2, hal. 210216, 2016.

[19] Kaleka W. M Deselina, "Transplantasi Karang Batu Marga Acropora pada Substrat Buatan di Perairan Tablolong Kabupaten Kupang,". Falsafah Sains., PPS 702, 2004. 